\title{
HEIDEGGER E ARISTÓTELES: O FENÔMENO DO MUNDO PERANTE A ARGUMENTAÇÃO LÓGICA DO MUNDO
}

\section{GUILHERME DEVEQUI QUINTILHANO' ${ }^{1}$ E EDER SOARES SANTOS ${ }^{2}$}

\begin{abstract}
RESUMO: O presente artigo articula a relação entre Heidegger e Aristóteles no desenvolvimento sobre o fenômeno do mundo (Welt) a partir do Livro IV da Metafísica. Na preleção de 1929-1930, Os conceitos fundamentais da metafísica, vislumbramos um caminho possível a ser percorrido que leva até o Livro IV da Metafísica aristotélica e ao debate com a tradição. Por consequência, o retorno para Ser e Tempo indica que o discurso adotado por Heidegger, na questão sobre o fenômeno do mundo, apresenta-se como uma tentativa de se distanciar dos enunciados lógicos da tradição a partir do motor imóvel aristotélico. Desse modo, enfatizamos dois pontos em Heidegger: 1) o seu resgate da tradição filosófica, ou seja, ele não destrói a tradição, pelo contrário, a filosofia heideggeriana e a construção de seus conceitos partem desse retorno; 2) a facilitação da compreensão do fenômeno de mundo em Ser e Tempo a partir da preleção de 1929-1930 e, por conseguinte, o motivo de nós voltarmos ao Livro IV da Metafísica de Aristóteles.
\end{abstract}

PALAVRAS-CHAVE: Mundo, metafísica, tradição filosófica, Heidegger, Aristóteles.

\begin{abstract}
This article describes the relationship between Heidegger and Aristotle regarding the development of the phenomenon of the world (Welt) based on Book IV of Aristotle's Metaphysics. Heidegger's lecture course of 1929-1930, The Fundamental Concepts of Metaphysics, shows a possible path to be followed that leads to Book IV of Metaphysics and to the debate with tradition. Consequently, going back to Being and Time shows that the discourse adopted by Heidegger regarding the question about the phenomenon of the world is an attempt to distance himself from the logical statements of tradition based on Aristotle's unmoved mover. Therefore, we highlight two points in Heidegger: 1) his resumption of the philosophical tradition, i.e., he does not destroy tradition, quite on the contrary, Heidegger's philosophy and the construction of his concepts are based on that return; 2) the lecture course of 1929-1930 helps understand the phenomenon of the world in Being and Time and this is the reason why we return to Book IV of Aristotle's Metaphysics.
\end{abstract}

KEYWORDS: World, metaphysics, philosophical tradition, Heidegger, Aristotle

\footnotetext{
${ }^{1}$ Mestre em Filosofia pela Universidade Estadual de Londrina (UEL). E-mail: guidevequi16@gmail.com.

2 Professor Associado no Departamento de Filosofia da Universidade Estadual de Londrina (UEL). Doutor em Filosofia pela Universidade Estadual de Campinas (Unicamp). E-mail: edersan@uel.br.
} 


\section{$O$ retorno para tradição}

O título da preleção de 1929-1930 elucida bem sobre o seu percurso: Os conceitos fundamentais da metafísica: mundo, finitude, solidão. Nosso interesse é sobre o fenômeno do mundo, pois mundo encontra-se atrelado, segundo Heidegger, como um dos conceitos da metafísica.

Já de saída, Heidegger apresenta sua intenção sobre a questão da metafísica, a saber: "dissipar radicalmente esta representação da metafísica como uma disciplina fixa" (HEIDEGGER, 2006, p. 33). Sendo assim, a pergunta, o que é mundo, encontra-se no cerne da questão metafísica e necessita ser retomada.

Outro ponto importante é a retomada histórica da palavra metafísica. A palavra metaphysica, no seu sentido latino, representa uma grande mudança em relação a sua concepção original, tendo assumido a característica de um termo que designa aquele tipo de conhecimento que se encontra além do sensível, sendo que "esta transformação do título não é de modo algum algo secundário. Com ela decide-se algo essencial: o destino da filosofia propriamente dita no Ocidente" (HEIDEGGER, 2006, p. 52, grifos do autor). No seu sentido

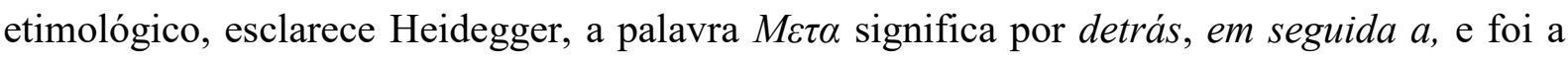
partir dessa primeira significação que surgiu o termo latino metaphysica (Cf. HEIDEGGER, 2006, p. 51). Porém, em grego esse termo tem outro significado: "quando vou atrás de uma coisa e a persigo, me movimento simultaneamente saindo de uma coisa e indo para uma outra. Isto é: mudo de algum modo radicalmente de direção" (HEIDEGGER, 2006, p. 52). O termo grego metafísica possui o significado de se lançar para fora, de se direcionar para um outro caminho. Contudo, de um conceito essencial na filosofia grega, metafísica se tornou simplesmente um conteúdo escolar (Cf. HEIDEGGER, 2006, p. 53).

Sobre a outra parte da palavra metafísica, physis, Heidegger diz:

\footnotetext{
Os acontecimentos que o homem experimenta em si, geração, nascimento, infância, maturidade, velhice, morte, não são de maneira nenhuma acontecimentos no sentido restrito e atual de um evento natural especificamente biológico, eles pertencem muito mais a vigência universal do ente, que concebe conjuntamente em si o destino humano e sua história (HEIDEGGER, 2006, p. 35-36).
}

Como resultado, há vários e diferentes modos de se referir a physis: "o que é o movimento, o lugar, o tempo, o que é o vazio, no qual o que está em movimento se movimenta, o que é na totalidade este ente que movimenta a si mesmo e o que é o primeiro motor" (HEIDEGGER, 2006, p. 44 - grifo nosso). Toda essa ciência da physis se orienta para a pergunta do primeiro motor, que mesmo sem nenhuma necessidade de conexão religiosa, 
remete ao divino, clama pelo divino: "Portanto, pergunta-se pelo ente na totalidade e, por fim, pelo divino [...] ou como diríamos hoje, mesmo que de maneira imprecisa, sobre a filosofia da natureza" (HEIDEGGER, 2006, p. 44). Desse modo, Heidegger retorna até Aristóteles, apresenta uma rápida noção sobre sua ciência e sobre a filosofia da natureza, aquela que se questiona pelo ente na totalidade, isto é, a pergunta pelo primeiro motor.

O filósofo da Floresta Negra procura inicialmente uma legitimidade para utilizar a palavra metafísica a partir de uma orientação na história da própria palavra porque "essa orientação reconduz-nos para o interior da filosofia antiga e fornece-nos ao mesmo tempo a possibilidade de vislumbrar os primórdios da própria filosofia ocidental na tradição em que nos encontramos" (HEIDEGGER, 2006, p. 45). Consequentemente, Heidegger aponta que, nossa tradição nos remete à filosofia grega e que, em função de más interpretações feitas da filosofia de Aristóteles, este acabou por se tornar o pai da metafísica da filosofia ocidental (Cf. HEIDEGGER, 2006, p. 47).

Não obstante, a pergunta pelo primeiro motor é a referência e apontamos este como o enunciado da metafísica ocidental, sendo que a tradição ao ter se apropriado ao seu modo dos conceitos aristotélicos - juntamente com sua lógica - passa a entender o mundo a partir de proposições que são verdadeiras ou falsas. Pensando especificamente sobre a questão do primeiro motor, o retorno ao livro IV da Metafísica de Aristóteles torna-se fundamental para compreender essa interpretação.

Sendo assim, o Livro IV da Metafísica será o escopo de nossa apresentação com alguns pontos em destaque: o problema do silogismo lógico e o axioma do princípio de não contradição. Esses dois elementos, em especial, influenciam no modo de conhecer o mundo e culmina na questão metafísica, isto é, a substância última das coisas.

\section{O Livro IV da Metafísica de Aristóteles}

No livro IV da Metafísica lê-se em suas duas últimas linhas: "De fato, existe algo que sempre move o que está em movimento, e o primeiro movente é, por si, imóvel" (ARISTÓTELES, 2005c, 1012b, 29-30). Eis aqui, o enunciado que a tradição tomou posse e disseminou como sendo a substância última das coisas.

Aristóteles dialoga contra o modo de pensar de seus antecessores ${ }^{3}$, para os quais o ser é dito em múltiplos significados, já para o estagerita, o ser sempre possui referência a uma

\footnotetext{
${ }^{3} \mathrm{Na}$ passagem 1004b, 29-31, Aristóteles apresenta como os filósofos de sua época pensavam a questão sobre o ser e aponta que quase todos estão de acordo que os seres e a substância são constituídos pelos contrários. Para
} 
unidade, um único princípio: "Portanto, se o primeiro é a substância, o filósofo deverá conhecer as causas e os princípios da substância" (ARISTÓTELES, 2005c, 1003b, 18). Aristóteles, dessa forma, afirma a noção de unidade das coisas, ou seja, a substância de cada objeto. Desse modo, o filósofo grego é contra a ideia do ser poder ser e não-ser ao mesmo tempo, por conseguinte, parte para explicação de seu axioma, o princípio de não contradição, que põe fim à questão do movimento das coisas.

\section{O PRINCÍPIO DE NÃO CONTRADIÇÃO}

$\mathrm{O}$ estudo dos axiomas relaciona-se ao estudo daquilo que é universal, e a substância primeira se encaixa nesse tipo de estudo (Cf. ARISTÓTELES, 2005c, 1005a, 33-35) e, "portanto, é evidente que a tarefa do filósofo e de quem especula sobre a totalidade da substância e sobre sua natureza, consiste em investigar também os princípios dos silogismos" (ARISTÓTELES, 2005c, 1005b, 5-7). Para Berti, o erro daqueles que discutiram os problemas antes de Aristóteles foi o de não possuírem a noção de substância (Cf. BERTI, 2010a, p. 337). A substância tem sua sustentação nos silogismos, isto é, possui um princípio seguro, aquele sobre o qual é impossível errar.

Aristóteles apresenta o seguinte princípio: "é impossível que a mesma coisa, ao mesmo tempo, pertença e não pertença a uma mesma coisa, segundo o mesmo aspecto" (ARISTÓTELES, 2005c, 1005b, 18-20). O filósofo grego fixa o princípio de todos os outros axiomas, a saber, o princípio da não contradição. Não obstante, ao apresentar a noção de substância última, necessariamente afirma-se o axioma do princípio de não contradição, razão pela qual, ele é o princípio seguro.

Ademais, é nessa passagem que a tradição filosófica fundamenta sua metafísica como substância última, aquilo que é, aquilo que permanece. E o texto de Aristóteles é a ferramenta de fundamentação desse pensamento, pois em 1006b, 9-10, quando ele diz que, "de fato, não se pode pensar nada se não se pensa em algo determinado" (ARISTÓTELES, 2005c). Aqueles que pensam que uma coisa pode ser e não ser ao mesmo tempo, não pensam na substância última das coisas (Cf. ARISTÓTELES, 2005c, 1007a, 21); e o que sustenta esta metafísica (ou modo de pensar) é o princípio de não contradição.

Aristóteles, em 1008a, 34-35, diz que, quando se estabelece que algo é verdadeiro, a negação é falsa, e quando a negação é verdadeira, a afirmação é falsa, mas nunca é possível afirmar e negar a mesma coisa. Só é possível falar em uma realidade quando ela é

Berti, Aristóteles estava debatendo com Platão a questão de ser e não-ser, isto é, o ser e os seus possíveis sentidos(Cf. BERTI, 2010b, p. 78). 
determinada (ARISTÓTELES, 2005c,1007b, 25-26). Só se pode fixar a verdade das coisas quando se diz que elas são de um só e mesmo modo, ou seja, somente quando algo permanece (ARISTÓTELES, 2005c, 1008b, 25-27). Este princípio também só é fixo por causa da justificativa do axioma do princípio de não contradição, que sustenta toda argumentação aristotélica.

Alguns comentadores são contra estas afirmações de Aristóteles. Para Lukasiewicz, por exemplo, o princípio de não contradição é tomado como lógico-ontológico: "para Aristóteles, a formulação lógica é logicamente de mesmo valor que (equivalente) a ontológica" (LUKASIEWICZ, 2005, p. 4), portanto, são representações de fatos objetivos. Mas para esse comentador, isto torna o princípio de não contradição indemonstrável, pois ele é insuficiente, já foi criado para um número limitado de objetos, ou seja, somente para substância das coisas (Cf. LUKASIEWICZ, 2005, p. 12).

O problema em Lukasiewicz é que ele quer demonstrar o princípio da não contradição e justifica que a lei da não contradição não é perceptível ${ }^{4}$ e que o mundo está numa mudança contínua e as contradições sempre vão continuar (LUKASIEWICZ, 2005, p. 21). Porém, ele afirma que, o princípio de não contradição é um princípio metafísico (LUKASIEWICZ, 2005, p. 16), e sim, neste ponto ele está correto. Com o fim da substância, a lei da não contradição não faz nenhum sentido, mas o texto de Aristóteles torna explícito nos últimos parágrafos do livro IV (supracitados), que sua base filosófica para encarar o mundo é a partir da substância e, portanto, o princípio da não contradição é o ponto chave para o desenvolvimento de sua teoria, da qual, a tradição tomou posse.

Aristóteles torna tangível o seu ponto de vista sobre como podemos dizer a verdade, ou seja, ele afirma que, se toda realidade está em movimento, não é possível dizer nada de verdadeiro. No entanto, o filósofo grego assegura que é dever de todos mostrar, para aqueles que acreditam no movimento, que existe uma realidade imóvel, e convencer a todos eles sobre tal permanência (ARISTÓTELES, 2005c, 1010a, 7-10).

Predicação lógica: o modo de conhecer mundo

A predicação lógica não está explicitamente apresentada nos textos de Aristóteles, desse modo, com o apoio dos comentadores torna-se mais claro apresentá-la, ainda que rapidamente. A predicação envolve o silogismo e é uma forma de conhecer o mundo a partir da fixação da substância última.

\footnotetext{
${ }^{4}$ Aristóteles afirma que em certas coisas não existem razão e é inútil buscar uma demonstração (ARISTÓTELES, $2005 \mathrm{c}, 1011 \mathrm{a}, 10)$, com isso o filósofo grego pode seguir com o princípio da não contradição, ou seja, não é possível apresentar uma demonstração deste princípio, pois ele é o princípio de uma demonstração e, por tal motivo, não pode ser demonstrado.
} 
Mas como enunciamos o mundo a partir do princípio de não contradição? Para Angioni, o princípio de não contradição é de suma importância para descrever o mundo, pois, sem ela, não teríamos uma comunicação consistente (Cf. ANGIONI, 2006, p. 46). Isso se torna uma necessidade lógica, pois "a conclusão é decorrência necessária das premissas" (ANGIONI, 2006, p. 63). Com efeito, ao concluir que x é um animal bípede, ele não pode não ser um animal bípede, é necessário que x seja um animal bípede. Dessa maneira, o princípio de não contradição entra em vigor, pois ao afirmar que $\mathrm{x}$ é bípede, $\mathrm{x}$ não pode, ao mesmo tempo, não ser bípede.

Portanto, o argumento de Aristóteles é que a semântica da predicação já pressupõe o princípio de não contradição: “Aristóteles parece retomar em bases mais fortes o princípio de que há predicados que significam uma só coisa" (ANGIONI, 2006, p. 67), e cada enunciado define algo no mundo.

E o que é a predicação lógica? É o enunciado que possui a forma $S$ é $P$ ou alguma forma que seja redutível a ela, em que se tem a pretensão de registrar esses fatos como verdade (Cf. ANGIONI, 2006, p. 17).

Acerca da estrutura da predicação, existem dois termos básicos: o sujeito e o predicado. Por fim, há também o operador copulativo. O sujeito é o assunto do qual se pretende falar e o predicado é aquilo que se propõe sobre o assunto já introduzido pelo termo sujeito $^{5}$ (Cf. ANGIONI, 2006, pp. 18-19).

É possível agora, apontar que, Aristóteles apresenta o mundo a partir de enunciados. Partindo desta pretensão de apresentar um estado de coisas do mundo como enunciados, ele apresenta sua ontologia a partir da teoria da predicação, pois envolve uma teoria semântica declarativa que se reporta objetivamente ao mundo.

A teoria da predicação é uma teoria a respeito das correlações entre, de um lado, as estruturas objetivas pelas quais as coisas se dão no mundo e, de outro, as estruturas lógico-linguísticas pelas quais pretendemos constatá-las e remeter a elas (ANGIONI, 2006, p. 20).

A lógica assume esse papel de que dois predicados podem ser verdadeiramente atribuídos a um sujeito (Cf. ANGIONI, 2010, p. 78), ou seja, o predicado significa de algo uno, e isto indica que o sujeito recebe a denominação expressa no predicado.

Para elucidar toda esta concepção até aqui apresentada, retornamos ao livro IV, no qual Aristóteles reitera que de um mesmo objeto não podemos falar que é e não é ao mesmo

\footnotetext{
${ }^{5}$ Nos Analíticos Anteriores, o Estagirista apresenta que quando não se tem um silogismo, por conseguinte, não é possível afirmar nada sobre o mundo, pois o termo médio não se aplica a nada, a nenhuma das premissas. $\mathrm{O}$ termo médio, "é o mesmo dizer que um termo está contido inteiramente num outro termo e dizer que um termo é predicado de um outro termo tomado universalmente" (ARISTÓTELES, 2005a, 24b, 28). Portanto, se X é predicado de todo $\mathrm{Y}$ e $\mathrm{Y}$ de todo $\mathrm{Z}, \mathrm{X}$ terá necessariamente que ser predicado de $\mathrm{Z}$.
} 
tempo, sendo estas afirmações contraditórias, ambas não podem ser verdadeiras concomitantemente (Cf. ARISTÓTELES, 2005c, 1011b, 14) e, por conseguinte, delas não é possível afirmar nada de verdadeiro. Portanto, de um mesmo objeto só é admissível negá-lo ou afirma-lo.

Assim, partindo do enunciado elementar já apresentado, só é possível afirmar verdade sobre as coisas (e sobre o mundo) se estas fazem parte do seu silogismo, que tem como base o princípio de não contradição. A partir da noção de substância, abre-se o caminho para afirmar o princípio da metafísica ocidental - a questão do motor imóvel. Princípio este que ordena o modo de conhecer o mundo objetivamente, a partir dos axiomas e que garante a permanência das coisas, isto é, a substancialidade.

Com essa apresentação do mundo como um problema da metafísica e o retorno para o centro da tradição, identificando as raízes do pensamento metafísico, o próximo passo é o desenvolvimento do fenômeno do mundo, com o intuito de apresentar o debate heideggeriano com a tradição e demonstrar a proximidade desse debate com Aristóteles, principalmente com a questão do desenvolvimento do fenômeno do mundo.

\section{O fenômeno do mundo}

A importância da identificação do fenômeno do mundo com a metafísica é que ela pode ser a ligação com a grande obra de 1927, todo o desenvolvimento da questão sobre o fenômeno do mundo se aproxima de uma resposta e tentativa de distanciamento do modo como a tradição lidou com tal problema. Esse embate é possível de ser verificado em Ser e Tempo e na preleção de 1929-1930, sendo que, nesta última, o filósofo alemão discorre sobre o caminho percorrido, o retorno na tradição.

O filósofo alemão apresenta o ente enquanto tal, este ente pertence à essência do mundo, "ao mundo pertence à abertura do ente enquanto tal, do ente enquanto ente" (HEIDEGGER, 2006, p. 351, grifos do autor). Em um primeiro momento, Heidegger demonstra o enquanto na forma de uma expressão linguística, por exemplo, ao falar do enquanto sempre se pensa algo junto, $a$ enquanto $b$, o ente enquanto tal.

No 'enquanto' reside uma ligação, e, com isto, dois elementos de ligação. Estes elementos não são apenas dois elementos, mas um é o primeiro e o outro é o segundo. Todavia, esta junção da ligação e dos elementos da ligação não está pairando livremente (HEIDEGGER, 2006, p. 369, grifos do autor).

A função do enquanto ocorre se o ente já estiver previamente dado. Este ente tornase expresso e constitui-se deste ou daquele modo: "Um $a$ que é $b$ está previamente dado: este 
ser- $b$ do $a$ é realçado expressamente no interior do "enquanto"” (HEIDEGGER, 2006, p. 369). Desta forma, o enquanto se apresenta numa simples proposição, $a$ é $b$, ou seja, $a$ é compreendido enquanto $b$. Não obstante, o enquanto, nessa estrutura, faz parte de uma proposição enunciativa simples, da qual se diz se é verdadeira ou falsa.

Uma proposição verdadeira corresponde ao que expressa, "isto é, quando nos presta informações através desta correspondência enunciativa sobre o que e sobre como a coisa é" (HEIDEGGER, 2006, p. 369), ela torna as coisas evidentes, por conseguinte, a proposição verdadeira contém uma abertura da coisa, isto é, a proposição que torna manifesto, o enquanto encontra-se lá.

A reconstrução do argumento heideggeriano apresenta três pontos principais, i) $\mathrm{O}$ enquanto liga dois elementos; ii) sua proposição simples: $a$ é $b$; iii) com essa proposição enunciativa simples, diz-se se é verdadeira ou falsa. Toda essa argumentação aparenta estar bem amarrada, algo que faz sentido, ou seja, algo que está por trás que a sustenta, a saber, a lógica pautada no princípio da não contradição.

Heidegger diz que, o problema do mundo é um problema da metafísica e agrega mais um elemento - que já identificamos no retorno a Aristóteles - a lógica: “A pergunta pela essência do mundo é uma pergunta metafísica. O problema do mundo enquanto problema fundamental da metafísica é trazido para o interior da lógica. A lógica é, consequentemente, a própria base da metafísica" (HEIDEGGER, 2006, p. 370). Metafísica e lógica estão imiscuída uma na outra.

E de fato [...] esta conexão é a base e o veio primordial de toda a metafísica ocidental, assim como de seus questionamentos, uma vez que a lógica, seguindo o fio condutor do $\lambda o ́ \gamma o \varsigma$ e de sua verdade, prescreve o modelo de discussão de todos os problemas metafísicos, isto é, de todos os problemas que envolvem a pergunta pelo ser (HEIDEGGER, 2006, p 370) ${ }^{6}$.

Lógica e metafísica são a conexão da metafísica ocidental, consequentemente, as discussões sobre o modo como é mundo, são discussões metafísicas. Heidegger não deixa de lado a questão sobre o discurso, ele argumenta que, a lógica é em si a proposição enunciativa, ela é uma forma proposicional: "Esta forma proposicional determinou decisivamente a doutrina do discurso em geral" (HEIDEGGER, 2006, p. 387). Isto é, o discurso lógico sobre o mundo que torna tudo "bonito" e que todo enunciado se sustenta.

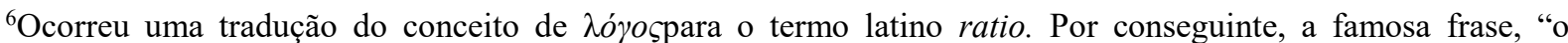
homem é um animal rationale", um ser vivo racional, foi implantada na história da filosofia e segue até hoje perpetuando e fugindo do verdadeiro significado, que é a possibilidade do discurso que possibilita a

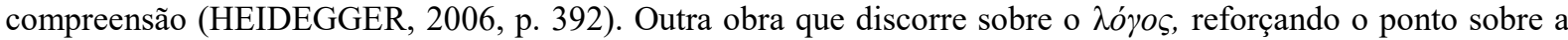
possibilidade do discurso e está no mesmo período, 1931, é Metafísica de Aristóteles 1-3: sobre a essência e a realidade da força.
} 
A interpretação do enquanto é decorrente do discurso lógico da metafísica consequente da proposição enunciativa: "Esta proposição enunciativa é em verdade uma construção necessária no interior do discurso humano, e, em especial, do discurso da cotidianidade, da atitude cotidiana do ser-aí em relação ao ente simplesmente dado" (HEIDEGGER, 2006, p. 389). Ela é uma construção que seduz e ao mesmo tempo abriga todos os riscos do entendimento vulgar, ela não é uma forma originária, mas essa proposição enunciativa pertence à essência do discurso cotidiano e o modo de conhecer o mundo, falando como ele é.

O discurso da tradição é metafísico, pois se pauta na lógica e tem como base de sua estrutura o princípio da não contradição que por sua vez decorre do enunciado sobre o motor imóvel identificado no Livro IV da Metafísica aristotélica. O modo como mundo é tratado pela tradição é um modo lógico, ou seja, o mundo é.

Com isso, atingimos parte da nossa empreitada neste texto, a saber: a de elucidar os caminhos apontados por Heidegger com o incremento do Livro IV da Metafísica e o princípio da não contradição, que sustenta toda argumentação da tradição.

O próximo passo é apresentar o desenvolvimento do fenômeno do mundo em Ser e Tempo, destacando as tentativas de distanciamento da tradição e ao mesmo tempo, sempre realizando uma ponte com a preleção de 1929-1930, pois essa obra é uma importante porta de entrada para obra de 1927 com alguns desdobramentos.

\section{O fenômeno do mundo em Ser e Tempo}

Ser e Tempo é uma obra de grande impacto no século XX devido aos novos conceitos e críticas por parte do autor a toda tradição. Desse modo, alguns estudos apontam a influência da filosofia prática de Aristóteles na obra de 1927, principalmente no que diz respeito à vida prática do Dasein. Ousamos dizer que, é praticamente unânime o discurso dos comentadores $^{7}$ que, o Livro VI da Ética a Nicômaco de Aristóteles é uma das maiores influências de Heidegger na referida obra ${ }^{8}$.

Porém, nosso percurso segue por outra rota, pois ao analisar primeiramente a preleção de 1929-1930 é possível apresentar desenvolvimento e alguns desdobramentos do fenômeno do mundo, com relação a Ser e Tempo e o retorno para tradição, isto é, Aristóteles em sua obra Metafísica no Livro IV, discorrendo sobre o motor imóvel e o princípio da não

\footnotetext{
${ }^{7}$ Franco Volpi, Escudero, Taminiaux, Walter Brogan e Zarader.

${ }^{8}$ Mas isso não é por acaso, pois na obra $O$ Sofista, de 1924, Heidegger menciona a influência do Livro VI da Ética aristotélica.
} 
contradição como base da argumentação lógica que a tradição incorporou e abordou sobre o mundo. Portanto, seguiremos com a apresentação do fenômeno do mundo com base no livro da Metafísica, vamos abordar a grande obra de 1927, principalmente a incorporação do Dasein e com alguns lampejos da preleção de 1929-1930.

Como mostrado anteriormente, o problema para Heidegger é que o mundo é dito por enunciados logicamente formulados classificando como as coisas são: o martelo é uma ferramenta, a mesa é para servir de apoio, a cadeira é para sentar. Desse modo, o enunciado $a$ é $b$ encontra-se no modo de apresentar o mundo.

Ainda nessa preleção, Heidegger, num tom imperativo diz: "Nos encontramos diante da tarefa descomunal de fazer esta tradição sair da estabilidade de suas bases" (HEIDEGGER, 2006, p. 414). O que isso quer dizer? Ser e Tempo foi uma investida para desestabilizar as bases dessa tradição de um modo mais geral e apresentando alguns conceitos de grande relevância para discussão ${ }^{9}$. Já a preleção de 1929-1930, caracteriza-se principalmente pela apresentação do regresso à tradição, a partir da questão metafísica com o alicerce do enunciado do motor imóvel. A obra de 1927 é fundamental para compreensão do debate com a tradição filosófica, juntamente com o escopo já apresentado, é possível entender a raiz de tal debate.

A analítica do Dasein, em Ser e Tempo, dispõe da sua constituição existencial, que não é estática, não é uma constituição única, ao contrário, possui vários modos, sendo um desses modos, a saber: Dasein encontra-se a partir de uma possibilidade, de ser assim (próprio) ou de outro modo (impróprio).“O que determina o Dasein é a possibilidade de ser ou não ser ele próprio. A analítica do Dasein edificar-se-á, assim, a partir da sua existencialidade, isto é, do que diz respeito ao seu ser" (PASQUA, 1993, p. 37). Dasein, portanto, é um ente sempre a partir de uma possibilidade.

Para Vattimo, o estudo do Dasein enquanto no mundo inicia-se com a cotidianidade, ou seja, Heidegger parte do mais comum, o ôntico. Este fato é importante no que diz respeito às possibilidades desse ente privilegiado, pois o seu ser é a sua própria possibilidade, mas isto não quer dizer que as outras possibilidades são suprimidas, pelo contrário, a cotidianidade torna possível pensar em todas as possibilidades, mesmo que algumas não sejam realizadas, “a possibilidade é, com efeito, o próprio sentido do conceito da existência [...] pelo fato de estar referido ao próprio ser como à própria possibilidade" (VATTIMO, 1996, p. 24). Tudo isto ocorre no mundo, portanto, uma das constituições do Dasein é ser-no-mundo.

\footnotetext{
${ }^{9}$ Por exemplo, Dasein enquanto ser-no-mundo, cotidianidade mediana, entre outros.
} 
Ser-no-mundo pode ser considerado como um todo em relação ao Dasein, pois este ente privilegiado se constitui como ser-no-mundo, "constitui um todo, no qual se mantêm juntos os diferentes momentos estruturais que compõem o Dasein” (PASQUA, 1993, p. 41). É a partir dessa expressão que as partes podem ser interpretadas, isto é, a partir do todo da constituição do Dasein como sendo ser-no-mundo, os outros modos de ser deste ente privilegiado são interpretados.

Podemos dizer que, Dasein e mundo são uma coisa só ${ }^{10}$, constituído por uma multiplicidade de momentos estruturais (HEIDEGGER, 2012, p. 169), a partir da cotidianidade mediana do ente privilegiado, Heidegger não trata de algo que está fora do mundo, ao contrário, o mundo faz parte do Dasein numa relação essencial e não acidental (PASQUA, 1993, p. 42).

A relação do Dasein com os entes, necessariamente ocorre quando o mundo é descoberto por ele, "pois a partir do mundo o ente poderá, então, revelar-se [...] e, assim, tornar-se acessível em seu ser simplesmente dado" (HEIDEGGER, 2011, p. 101). A abertura do mundo é necessária para a manifestação dos entes do interior do mundo. A diferença do Dasein em relação aos entes do interior do mundo ${ }^{11}$ é que ele possui uma compreensão prévia no seu modo factual $^{12}$ (Cf. HEIDEGGER, 2011, p. 102).

E o modo que ele conhece o mundo, não é algo que está resguardado para si, pelo contrário, encontra-se fora, junto ao ente do interior do mundo que lhe vem ao encontro no mundo já descoberto previamente, desse modo, ocupar-se, primeiramente é visualizar, encarar sem pressa, sendo o ente do interior do mundo é interpretado em um sentido amplo. Porém, a mera descrição do mundo não é uma forma de conhecê-lo, pois, assim, temos uma visão unívoca do mundo (Cf. HEIDEGGER, 2011, p. 110).

Desse modo, Heidegger apresenta mundo como um momento constitutivo do ser-nomundo, isto é, a cotidianidade mediana.

Quando perguntamos ontologicamente pelo 'mundo', de modo algum abandonamos o campo temático da analítica do Dasein. 'Mundo' não é ontologicamente uma

\footnotetext{
${ }^{10}$ François Jaran, em seu artigo, Toward a metaphysical freedom: Heidegger'sproject of a metaphysics of Dasein, faz uma leitura que se encaminha para uma possível ruptura entre Dasein e 'mundo', ou seja, para este autor existe a possibilidade de uma dicotomia (Cf. JARAN, 2010, p. 214).

${ }^{11}$ A diferença do Dasein em relação aos entes é que ele está aí, ele é um ser-no-mundo que possibilita abertura de espaço para os entes do interior do mundo. Não obstante, ele também possui uma relação ôntica, mas ele não é velado, pois dispõe de uma compreensão ontológica de si mesmo.

${ }^{12} \mathrm{O}$ factual ou factualidade são modos próprios do Dasein, são modos como ele é a cada vez em relação a um ente do interior do mundo. Pois, a partir do momento em que ele está familiarizado e habituado com o mundo, este ente privilegiado torna-se preocupado com o mundo em que habita e se ocupa com os entes do interior do mundo.
} 
determinação do ente que em sua essência o Dasein não é, mas um caráter do Dasein ele mesmo (HEIDEGGER, 2012, p. 199-201, grifo do autor). ${ }^{13}$

Pode-se perceber que, o autor de Ser e Tempo, argumenta com alguma distância em relação à tradição filosófica, pois considera o fenômeno do mundo a partir da cotidianidade mediana do Dasein, que decorre dos vários modos de se ocupar com o mundo: "Como se viu, o modo mais imediato de lidar não é o conhecer meramente perceptivo e sim a ocupação no manuseio e uso, a qual possui um 'conhecimento' próprio” (HEIDEGGER, 2011, p. 115 grifos nosso).

O modo de conhecer os entes do interior do mundo é pelo seu uso cotidiano, por exemplo, quando abro a porta, faço uso do trinco. Porém, é na cotidianidade do mundo circundante que os objetos vêm ao encontro do Dasein, que se ocupa no manuseio e afasta toda e qualquer interpretação corrente que possa encobrir está ocupação com os entes: "Na lida, encontram-se instrumentos de escrever, de medição, de costura, carros, utensílio. Cabe assim expor o modo de ser do instrumento" (HEIDEGGER, 2011, p. 116). Portanto, o modo de ser do instrumento deve ser evidenciado dentro da sua instrumentalidade, pois ele nunca é só, ele faz parte de um todo instrumental ${ }^{14}$.

Este fazer corriqueiro, ou a lida com os entes do interior do mundo não caracteriza que o mundo seja compreendido como uma aglomeração dos entes. Os entes estão jogados no mundo: "o mundo não é ele mesmo um ente do-interior-do-mundo e, no entanto, o mundo determina de tal modo o ente do-interior-do-mundo que este só pode vir-de-encontro e o ente descoberto só pode se mostrar em seu ser, na medida em que 'se dá' mundo" (HEIDEGGER, 2012, p. 221). O mundo se dá a partir das possibilidades do Dasein no interior da lida de sua ocupação na cotidianidade.

O mundo circundante [...] é um mundo onde vamos e vimos, onde [...] nos preocupamos com mil coisas ao mesmo tempo, encontramos o ente em, e através de, o uso que dele fazemos. O mundo circundante é um mundo do qual temos os usos, e o plural é essencial pois marca a dispersão de um Dasein diversamente ocupado (FRANCK, 1986, p. 52).

O ser-no-mundo cotidiano possui modos de ocupação em relação aos entes do interior do mundo e, por conseguinte, faz aparecer algumas determinações possíveis desses entes. O Dasein, portanto, encontra-se lançado na sua cotidianidade em meio aos entes do

\footnotetext{
${ }^{13}$ A relação ôntico-ontológica do Dasein ocorre nesta situação, pois a investigação do mundo também passa pelo ente do interior do mundo.

${ }^{14} \mathrm{~A}$ ideia do todo instrumental vem a partir do nexo com outro instrumento. [...] escritório, escrivaninha, pena, tinta, papel, pasta, mesa, lâmpada, móveis, janelas, portas, quarto. Essas 'coisas' nunca se mostram de imediato separadas umas das outras, vindo depois, numa como que soma de coisas reais, a preencher um quarto (HEIDEGGER, 2012, p. 211). O que vem ao encontro - o quarto - não é tematicamente apreendido, mas se torna um instrumento de morar.
} 
interior do mundo que, vez e outra, estão à mão ${ }^{15}$ : “O ser-no-mundo preocupado relaciona-se então com uma multiplicidade de utensílios" (FRANCK, 1986, p. 53).

É possível notar que Heidegger não eleva a formação de mundo para um outro plano ou algo fora de si, mas considera que a formação de mundo está aí, presente no cotidiano, no ocupar-se com as coisas que estão ao alcance da mão. A filosofia é um fazer cotidiano de tal e tal modo. "No âmbito de uma ocupação fática, deixar e fazer de tal modo que o manual seja como ele agora é e com o que ele é assim" (HEIDEGGER, 2011, p. 135). O modo como a tradição lidou com o mundo, logicamente pautado no princípio da não contradição e apontando para os objetos, enunciando como eles são, determinando assim o que ele pode ser, não faz parte da investigação heideggeriana.

Sendo assim, em Ser e Tempo, mundo é descoberto pelo Dasein, pois ele é o ente familiarizado com o mundo em que habita e, consequentemente, torna-se preocupado com este mundo e ocupa-se com os entes do interior do mundo a partir da cotidianidade.

Mas isso não é o mesmo que a tradição realizou, ou seja, conhecer o mundo a partir de enunciados lógicos? O que muda quando se parte da cotidianidade? A diferença com relação à tradição é que Dasein é um ente que não possui essência, ele é possibilidade, "a possibilidade como forma de ser do Dasein é anterior a qualquer determinação positiva" (ESCUDERO, 2016, p. 162, grifo do autor). Esse ente privilegiado não procura a substância última dos entes do interior do mundo que vêm ao encontro, ele conhece conforme lida com eles.

Esse modo de conhecer as coisas do mundo vai diretamente contra o modo como a tradição tratou essa questão, principalmente a relação sujeito-objeto que é um modo não originário de acesso para o mundo (ESCUDERO, 2016, p. 168). "Como se viu, o modo mais imediato de lidar não é o conhecer meramente perceptivo e sim a ocupação no manuseio e uso, a qual possui um 'conhecimento' próprio" (HEIDEGGER, 2011, p. 115). O conhecimento dos entes do interior do mundo encontra-se no seu uso, na lida cotidiana.

Resgatando a interpretação da preleção de 1929-1930, a mostração, isto é, o ver o ente ao redor - em Ser e Tempo é chamado de circunvisão - quebra com o princípio de não contradição, pois ao se ocupar com uma caixa, Dasein pode tê-lo conhecido como um

\footnotetext{
15“'O que está imediatamente à mão caracteriza-se por recolher-se na sua manualidade para, justamente assim, ficar à mão" (HEIDEGGER, 2011, p. 118). Portanto, o ente que está à mão na lida cotidiana do Dasein é a obra a ser produzida em cada caso do qual se ocupa. "É a obra que sustenta a totalidade das referências na qual o instrumento vem ao encontro" (HEIDEGGER, 2011, p. 118). Nesse sentido, pode-se argumentar que, a atitude prática é mais natural que a contemplação, pois a obra a ser produzida, que é um para que, explicita o modo de ser dos instrumentos, deixa e faz vir ao encontro suas possibilidades de manuseio.
} 
instrumento, por exemplo, de sentar e não simplesmente como um instrumento de armazenar coisas. ${ }^{16}$ Por conseguinte, Dasein lidou com o instrumento de um tal modo.

Um ponto importante é que Heidegger delimita o espaço não simplesmente preenchido por coisas, como um aglomerado de objetos espalhados, o espaço encontra-se oculto daquilo que está à mão. $\mathrm{O}$ espaço, portanto, não é formado pelo acúmulo de coisas subsistentes. O espaço que é descoberto como a espacialidade do todo instrumental, a partir da circunvisão do ser-no-mundo, pertence sempre a cada vez ao ente ele mesmo como seu lugar-próprio. Portanto, o espaço não é determinado, a espacialidade ocorre na totalidade conjuntural em relação aquilo que está à mão (HEIDEGGER, 2012, p. 305).

O Dasein tem como uma de suas características a familiaridade, pois ser-no-mundo é algo familiar para este ente. Por conseguinte, no mundo circundante, aquilo que não é familiar para o ente privilegiado, aquilo que está faltando na circunvisão, o surpreende: "é frequente que no não encontrar algo em seu lugar-próprio a região dos lugares-próprios se torne pela primeira vez como tal expressamente acessível” (HEIDEGGER, 2012, p. 305 - grifos do autor). Torna-se acessível, pois os espaços ainda estão encobertos.

Essa noção do espaço e sua relação com os entes que vem ao encontro é retomada na preleção de 1929-1930, sobre o mal posicionamento do quadro num determinado auditório:

Se não pensássemos esta sala como um auditório, mas como um espaço de dança, então este quadro se encontraria totalmente bem posicionado [...] este quadro encontra-se mal posicionado nesta sala, que é um auditório e que pertence a universidade. (HEIDEGGER, 2006, p. 442).

O que Heidegger faz é se concentrar naquilo que está manifesto junto ao ente. “Os enunciados só podem ser inseridos no que já está manifesto na totalidade" (HEIDEGGER, 2006, p. 443). Isto é, o quadro só se encontra mal posicionado por causa da abertura do auditório em que se encontra o mau posicionamento do quadro. Por conseguinte, falamos a partir de um ente que já está manifesto na totalidade ${ }^{17}$, sendo que, no exemplo, a totalidade do auditório é compreendida de antemão.

O enunciado não é originário e nem autônomo, mas é a partir daquilo que está aí, numa pré-condição de abertura, que o ente pode ser manifesto. "O decisivo desta interpretação do enunciado é o fato de não formarmos juízos em relação a um objeto isolado, mas de falarmos neste juízo a partir da totalidade já experimentada e conhecida, que

\footnotetext{
${ }^{16}$ E essa seria sua finalidade, pois ao conhecer mundo pelos enunciados lógicos um engradado tem como finalidade armazenar garrafas.

17 “'Todo ente a cada vez acessível, nós mesmos incluídos, é abarcado por esta totalidade [...] este 'na totalidade', o mundo, é o que permite a abertura dos múltiplos entes em seus contextos ontológicos diversos - outros homens, animais, plantas, coisas materiais, obras de arte, isto é, tudo o que conseguimos encontrar enquanto ente" (HEIDEGGER, 2006, p. 453-454, grifo do autor).
} 
chamamos auditório" (HEIDEGGER, 2006, p. 444, grifo nosso). Temos então mais uma retomada de Ser e Tempo, pois, antes de enunciar a condição prévia, é de suma importância, que tal condição seja a possibilidade de abertura deste ente que está aí e essa interpretação não forma juízo de objetos isolados, mas a partir de um conjunto, de um todo, permitindo a abertura de uma possibilidade que seja anterior à lógica.

Aquilo que é anterior à lógica em relação ao ente agrega-se ao princípio do ente na totalidade. "Toda enunciação acontece sobre a base de uma tal integração, isto é, sobre a base de uma formação prévia deste na 'totalidade"” (HEIDEGGER, 2006, p. 446). Essa totalidade não é a essência, aquilo é, ela é diversa e muda a todo momento na cotidianidade do Dasein, ou seja, não se diz que o mundo é.

"Mundo como abertura do ente enquanto tal na totalidade. Se tomarmos imediatamente esta determinação do mundo, é fácil perceber que não se fala aí absolutamente nada do enunciado e do $\lambda o ́ \gamma o \varsigma "$ (HEIDEGGER, 2006, p. 448) ${ }^{18}$. Ou seja, pensar a questão do mundo a partir do $\lambda o ́$ yo $\varsigma^{19}$ ou interpretar o mundo a partir da ratio (razão), ambos não dão conta do problema, pois, de fato, partindo desses conceitos, a questão proposta não é reconhecida. " $\lambda o ́ \gamma o \varsigma$, ratio, razão, espírito: todas estas palavras são termos encobridores do problema do mundo" (HEIDEGGER, 2006, p. 449, grifo do autor).

Para finalizar a ideia dessa multiplicidade do mundo e a tentativa de distanciamento do discurso lógico da tradição, vamos utilizar mais um exemplo de Heidegger, que faz analogia com uma floresta, na qual estamos diante de inúmeras árvores, mas não vemos a floresta: "Em relação às árvores singulares e à sua aglomeração, a floresta é algo diverso" (HEIDEGGER, 2006, p. 445-446). Ou seja, a floresta não é a soma das árvores, "ao contrário, ela é aquilo, a partir do que as muitas árvores se mostram como pertencentes a uma floresta" (HEIDEGGER, 2006, p. 446). Precisamos nos ater neste novo modo de enunciar o mundo, a manifestação do todo. "Justamente este lugar, contudo, em que já sempre nos movimentamos, é o que designamos de início esquematicamente através da expressão "na totalidade"" (HEIDEGGER, 2006, p. 446).

\section{Conclusão}

Podemos concluir que, a argumentação heideggeriana sobre o fenômeno do mundo é um debate direto com a tradição, não com o intuito de destruí-la, pelo contrário, a preleção de

\footnotetext{
18 'Uma vez que o 'enquanto' é, porém, um momento estrutural do que chamamos mundo e mundo é tomado como a abertura do ente enquanto tal na totalidade, com aquele acontecimento fundamental [...] nos deparamos com o acontecimento, no interior do qual tem lugar o que chamamos formação de mundo" (HEIDEGGER, 2006, p. 448, grifo do autor).

${ }^{19}$ Que faz parte da tradição grega, mas aqui foi interpretado a partir de Aristóteles.
} 
1929-1930, mostra que o retorno para o centro dessa tradição é importante para identificar o caminho que foi feito e, posteriormente, apresentar um discurso que confronte construtivamente toda a tradição filosófica - principalmente em Ser e Tempo - que aqui foi identificada como metafísica a partir do enunciado do motor imóvel.

Iniciar o texto pela preleção de 1929-1930 teve o intuito de apresentar o resgate histórico e a tentativa de justificar a importância do Livro IV da Metafísica de Aristóteles no desenvolvimento do fenômeno do mundo neste período entre 1927 (Ser e Tempo) até meados de 1931.

Portanto, a preleção já mencionada, encontra-se como um texto que torna possível compreender o desenvolvimento do fenômeno do mundo em Ser e Tempo, pois a relação do mundo com a metafísica (que é o resgate histórico em Aristóteles) torna-se o fio condutor para o início do desenvolvimento para tal problema e, consequentemente, do discurso adotado pelo filósofo na grande obra de 1927. Incorporando o Livro IV da Metafísica aristotélica, o cenário para o debate com a tradição se completa, pois o desenvolvimento do fenômeno do mundo se encaminha para um distanciamento do discurso lógico da tradição filosófica.

\section{REFERÊNCIAS BIBLIOGRÁFICAS}

ANGIONI, Lucas. Prioridade e substância na metafísica de Aristóteles. Dois Pontos, [S.1.], v. 7 , n. 3, jul. 2010. ISSN 2179-7412. Disponível em: $<$ http://ojs.c3sl.ufpr.br/ojs/index.php/doispontos/article/view/14818>. Acesso em: 14 Mai. 2015. doi:10.5380/dp.v7i3.14818. da Unicamp, 2006.

Introdução à teoria da predicação em Aristóteles. Campinas, SP: Editora

ARISTÓTELES. Analiticos Anteriores. In: Òrganon. Tradução Edson Bini. $2^{\mathrm{a}}$ edição. Bauru, SP: EDIPRO, 2005a. SP: EDIPRO, 2005b.

Analíticos Posteriores. In:Órganon. Tradução Edson Bini. 2a edição. Bauru, $2005 \mathrm{c}$. . Metafísica. Tradução Marcelo Perine. 2a edição. São Paulo: Edições Loyola,

BERTI, Enrico. No princípio era a maravilha. Tradução Fernando Soares Moreira. São Paulo: Edições Loyola, 2010a.

. Novos estudos aristotélicos I: epistemologia, lógica e dialética. Tradução de Élcio de Gusmão Verçosa Filho. São Paulo: Edições Loyola, 2010 b.

ESCUDERO, Adrián. Guía de lectura de Ser y Tiempo de Martin Heidegger, vol. 1. Herder Editorial, Barcelona, 2016.

Guía de lectura de Ser y Tiempo de Martin Heidegger, vol. 2. Herder Editorial, Barcelona, 2016. 
66, p. 3-29, Mayo 2011.

Heidegger, lector de la retórica aristotélica. Diánoia, México, v. 56, n.

FLORENTINO, Antonio Neto. Nishitani e o tradicional problema da superação da metafisica. In: Budismo e filosofia em diálogo. Antonio Florentino Neto e Oswaldo Giacoia Jr. (orgs). - Campinas, SP: Editora PHI, 2014.

FRANCK, Didier. Heidegger e o problema do espaço. Tradução João Paz. Lisboa, Portugal: Instituto Piaget, 1986.

JARAN, François. Toward a metaphysical freedom: Heidegger's project of a metaphysics of Dasein. InternationalJournalofPhilosophicalStudies. Vol. 18(2), 205-227.2010.

HEIDEGGER, Martin. Os conceitos fundamentais da metafísica: mundo, finitude, solidão. Tradução Marco Antônio Casanova. Rio de Janeiro: Foresen Universitária, 2006.

Unicamp, 2012. . Ser e Tempo. Tradução Fausto Castilho. Campinas: Editora da . Ser e Tempo. Tradução Marcia Sá Cavalcante Schuback, $5^{a}$ edição.

Petrópolis, Rio de Janeiro: Editora Vozes, 2011.

LUKASIEWICZ, Jan. Sobre a lei da contradição em Aristóteles. In: ZINGANO, Marco. Sobre a metafísica de Aristóteles: textos selecionados. São Paulo: Odysseus Editora, 2005.

MANSION, Suzanne. A primeira doutrina da substância: a substância segundo Aristóteles.In: ZINGANO, Marco. Sobre a metafísica de Aristóteles: textos selecionados. São Paulo: Odysseus Editora, 2005.

PASQUA, Hervé. Introdução à leitura de Ser e Tempo de Martin Heidegger. Tradução Joana Chaves. Instituto Piaget. Lisboa, 1993.

VATTIMO, Gianni. Introdução a Heidegger. Tradução João Gama. Lisboa, Instituto Piaget, 1996.

\section{Obras de Heidegger utilizadas, mas não citadas ou mencionadas:}

HEIDEGGER, Martin. Introdução à filosofia. Tradução Marco Antonio Casanova. São Paulo, Martins Fontes, 2008.

. Metafísica de Aristóteles 1-3: sobre a essência e a realidade da força. Tradução Enio Paulo Giachini. Petrópolis, RJ: Vozes, 2007.

. Sobre a Essência do fundamento. Tradução e notas Ernildo Stein. São Paulo: Editora Nova Cultural, 1999 - Col. Os Pensadores.

\section{Obras dos comentadores mencionados:}

BROGAN, Walter A. Heidegger and Aristotle: the twofoldness of Being. State University of New York, 2005.

ESCUDERO, Adrián. Heidegger e a filosofia prática de Aristóteles. Tradução Jasson da Silva Martins, José Francisco dos Santos. São Leopoldo, RS: Nova Harmonia, 2010.

TAMINIAUX, Jacques. Leituras da Ontologia Fundamental: ensaios sobre Heidegger. Tradução João Carlos Paz. Lisboa, Portugal: Instituto Piaget, 1995. 
VOLPI, Franco. Heidegger e Aristóteles. Tradução José Trindade dos Santos. São Paulo: Edições Loyola, 2013.

ZARADER, Marlène. Heidegger e as palavras da origem. Tradução João Duarte. Instituto Piaget. Lisboa, 1998. 